\title{
Thin Film Nanostructured ATO and ATO Based Composite Anodes for Li-Ion Batteries
}

\author{
O. Cevher, M.O. Guler, U. Tocoglu, T. Cetinkaya, H. Akbulut and S.C. Okumus \\ Sakarya University, Engineering Faculty, Department of Metallurgical and Material Engineering \\ Esentepe Campus, Sakarya, Turkey
}

\begin{abstract}
In this study, antimony doped tin oxide films were deposited on multiwall carbon nanotube buckypaper and Cr coated stainless steel substrates using a radio frequency magnetron sputtering process in a mixed oxygen/argon $(5 / 95)$ gas environment. The depositions of antimony doped tin oxide on the multiwall carbon nanotube buckypaper and stainless steel substrates were carried out using the parameters organized as: target composition antimony doped tin oxide $\left(\mathrm{SnO}_{2}: \mathrm{Sb}=90: 10 \mathrm{wt} \%\right)$; total system pressure $1 \mathrm{~Pa}$; sputtering power $(\mathrm{RF}) 100 \mathrm{~W}$. The surface morphology of the antimony doped tin oxide films was investigated by field emission scanning electron microscopy. The crystallographic structure of the samples was determined by X-ray diffraction. The electrochemical properties of antimony doped tin oxide and antimony doped tin oxide-multiwall carbon nanotube nanocomposite anodes containing CR2016 cells were measured by galvanostatic charge-discharge experiments.
\end{abstract}

DOI: 10.12693/APhysPolA.125.296

PACS: 61.72.uj, 88.30.rh, 82.47.Aa

\section{Introduction}

With the development of portable electronics, numerous studies have focused on the anode materials that have higher $\mathrm{Li}^{+}$storage capacities than the carbonaceous materials [1-3]. Tin oxide is an attractive material as a potential substitute for the conventional graphite anode in Li-ion batteries, because the theoretical capacity of $\mathrm{SnO}_{2}$ $\left(1494 \mathrm{mAh} \mathrm{g}^{-1}\right)$ has been estimated to be superior to that of graphite $\left(372 \mathrm{mAh} \mathrm{g}^{-1}\right)$ [4-7]. However, a major problem of anode materials for lithium-ion batteries is the significant volume change (ca. 300\%) occurring during the alloying and de-alloying processes, which may induce damage to the anodes and cause very poor long-term cyclability. Moreover, the formation of amorphous $\mathrm{Li}_{2} \mathrm{O}$ matrix causes a huge irreversible capacity during the first cycle [8-10]. Many efforts have been devoted to avoid the capacity fading. The Sb doping was found to increase the electrical conductivity and mechanical stability of the anode, thereby leading to improved electrochemical properties [11]. The incorporation of carbon nanotubes (CNTs) is one of the most well-established methods to reduce the volume expansion as well as to improve the electronic conductivity of the electrodes [12, 13].

It is well known that increasing the electrochemical performances of the metal oxide anodes can be achieved by producing nanosized grains, thin films, mesoporous structures and nanocomposites, containing buffer components. In this study, it is aimed to provide all the above mechanisms to produce high reversible capacity with long cycle life. To achieve our purposes Sb doping was targeted to decrease grain size of $\mathrm{SnO}_{2}$ with a thin film and mesoporous structure which emanated from a skeleton like multiwall carbon nanotube (MWCNT) network. MWCNTs were aimed to produce as buckypapers to provide load transfer from the antimony doped tin oxide (ATO) matrix caused from the volume increase dur- ing insertion of Li ions. The top surfaces of the MWCNTs were aimed to coat the active materials of ATO whereas the bottom of the buckypaper is thought to get bare MWCNTs to provide high conductivity as a current collector.

\section{Experimental}

MWCNTs (production by scalable CVD method, purity: MWCNTs $>95 \%$, diameter $>50 \mathrm{~nm}$, length $>5 \mu \mathrm{m}$ ) were purchased from Arry International Group Limited (Germany). MWCNTs were heated in air at $350{ }^{\circ} \mathrm{C}$ for $2 \mathrm{~h}$ and then soaked in hydrochloric acid for $24 \mathrm{~h}$. The precipitate was rinsed with deionized water and dried at $40^{\circ} \mathrm{C}$. MWCNTs were chemically functionalized by ultrasonification in a mixture of sulfuric acid and nitric acid (3:1) for $8 \mathrm{~h}$. Functionalized multiwall carbon nanotubes (fMWCNTs) were washed with deionized water and dried at $40^{\circ} \mathrm{C}$ for $24 \mathrm{~h}$. fMWCNTs $(20 \mathrm{mg})$ were dispersed with $100 \mathrm{mg}$ of SDS in $50 \mathrm{~mL}$ of deionized water and sonicated for $1 \mathrm{~h}$. PVDF membranes with a pore size of $220 \mathrm{~nm}$ were used in vacuum filtration (Fig. 1). Then the MWCNT buckypapers were separated from the PVDF membrane, further compacted, and dried at $40^{\circ} \mathrm{C}$ for $24 \mathrm{~h}$. The average thickness of the produced MWCNT buckypapers is approximately $50 \mu \mathrm{m}$ and their diameter about $16 \mathrm{~mm}$.

The coating process has been performed in a multifunctional magnetron sputtering PVD unit equipped with RF units. ATO films were deposited on $\mathrm{Cr}$ coated stainless steel and MWCNT buckypaper (Fig. 1) using $\mathrm{RF}$ magnetron sputtering. The target was a $\mathrm{SnO}_{2}: \mathrm{Sb}$ disc $\left(\mathrm{SnO}_{2}: \mathrm{Sb}=90: 10 \%\right.$ in weight $)$. The $\mathrm{RF}$ power was $100 \mathrm{~W}$. ATO films were deposited under $\mathrm{O}_{2} / \mathrm{Ar}(5 / 95)$ gas mixture at a constant working pressure of $1.0 \mathrm{~Pa}$. The flow rate of $\mathrm{Ar}$ and $\mathrm{O}_{2}$ gases was fixed by a TDZM- 


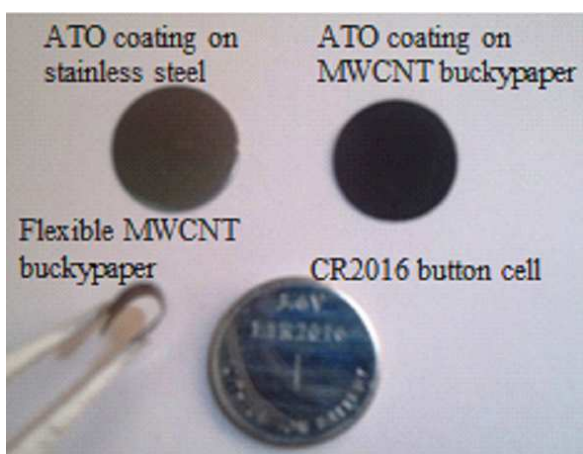

Fig. 1. ATO anode and ATO-MWCNT nanocomposite anode.

-III mass flow controller. The substrate was not heated deliberately and not measured.

The morphology of ATO and ATO-MWCNT nanocomposites was examined by scanning electron microscopy (FESEM) (JEOL JSM-7000F). The crystalline structures of ATO, MWCNT and ATO-MWCNT nanocomposites were characterized by X-ray diffraction (XRD) technique. The XRD patterns of ATO, MWCNT and ATO-MWCNT nanocomposites were obtained by an X-ray diffractometer (Rigaku D/MAX 2000 with a multipurpose attachment) using $\mathrm{Cu} K_{\alpha}$ radiation $(\lambda=1.54056 \AA)$. The scan rate used was $1^{\circ} / \mathrm{min}$ and the scan range was from $10^{\circ}$ to $90^{\circ}$. The mean grain size as calculated by Scherrer's formula [14]:

$$
D=\frac{0.9 \lambda}{B \cos \theta},
$$

where $D$ is the mean grain size, $\lambda$ is the $\mathrm{X}$-ray wavelength, $B$ is the corrected full-width at half maximum (FWHM), and $\theta$ is the Bragg angle.

Coin-type (CR2016) test cells were assembled in an argon-filled glove box using the ATO and ATO-MWCNT materials as the working electrode, a lithium metal foil as the counter electrode, a microporous polypropylene (PP) membrane (Cellgard 2300) as the separator, and $1 \mathrm{M}$ solution of $\mathrm{LiPF}_{6}$ in ethylene carbonate (EC) and dimethyl carbonate (DMC) (1:1 by weight) as the electrolyte. The cells were aged for $24 \mathrm{~h}$ before measurements. The electrochemical performance of ATO-MWCNT nanocomposite anodes was evaluated by galvanostatic dischargecharge measurement using a computer-controlled battery tester between $0.05 \mathrm{~V}$ and $3.0 \mathrm{~V}$.

\section{Results and discussions}

Figure 2a shows FESEM images of ATO nanoparticles deposited by RF magnetron sputtering on $\mathrm{Cr}$ coated stainless steel. It can be clearly seen that the ATO thin films have a relatively smooth and dense surface. Figure $2 \mathrm{~b}$ shows FESEM images of ATO nanoparticles deposited by RF magnetron sputtering on MWCNT buckypaper. The ATO nanoparticles is covering the surface of the MWCNTs continuously and uniformly in the
$\mathrm{SnO}_{2}: \mathrm{Sb}-\mathrm{MWCNT}$ samples. Chemical functionalization of MWCNTs is expected to play an essential role in tailoring the properties of material. Compared with pristine surface of MWCNTs, nanoparticles are easy to attach nanotube surfaces with functional groups (such as carboxylic and hydroxyl groups). It has been reported that functional groups on carbon nanotubes can act as nucleation centers for metal ions [15].

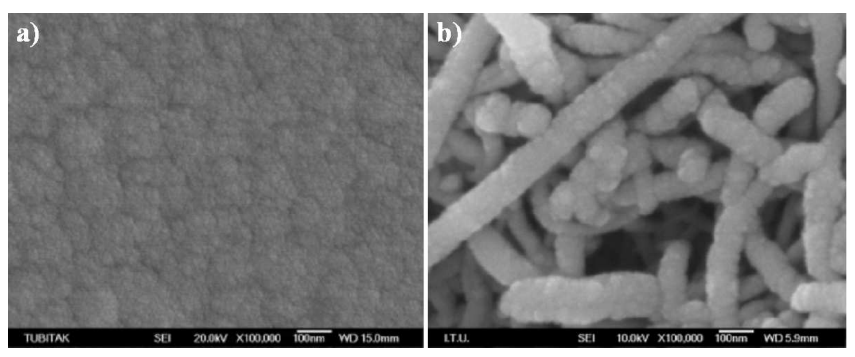

Fig. 2. Surface FESEM images: (a) ATO coating on stainless steel and (b) ATO coating on MWCNT buckypaper.

ATO-MWCNT nanocomposite electrode materials with large surface areas have led to multiple advances in the performance of $\mathrm{Li}$ ion batteries by providing shorter path lengths for both electron and $\mathrm{Li}$ ion transport, higher electrode/electrolyte contact area, better accommodation of the strain of the $\mathrm{Li}$ ion insertion/extraction, and much easier conductive pathways via the MWCNTs.

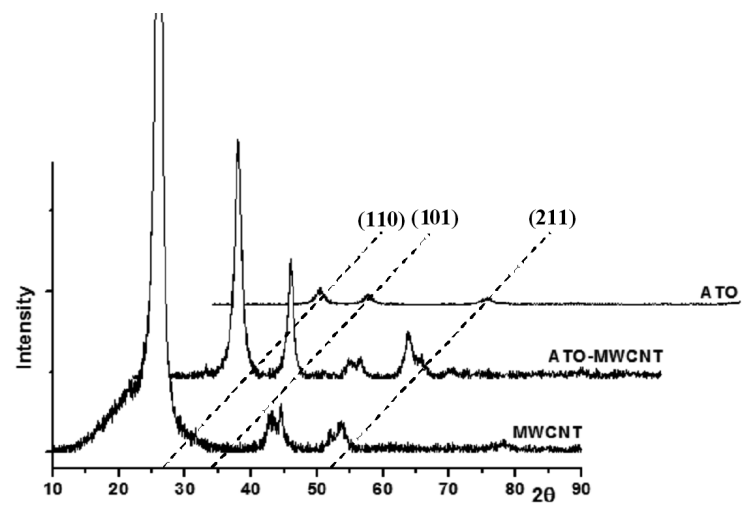

Fig. 3. The XRD patterns of ATO, ATO coated MWCNTs, and MWCNT buckypaper.

The crystallographic structure of ATO films deposited at $100 \mathrm{~W}$ RF power and $5 \%$ oxygen partial pressure was presented in Fig. 3. The diffraction peaks indicate that tin oxide exists in cassiterite tetragonal (rutile type) structure (JCPDS card number 00-041-1445). The (110), (101), and (211) diffraction peaks were observed for the ATO films. Figure 3 shows XRD pattern of fMWCNT buckypaper. The characteristic peaks of the (002) and (101) reflections are observed at about $26^{\circ}$ and $43^{\circ}$ for the MWCNT. The XRD patterns of ATO-MWCNT nanocomposites show cassiterite structures. 
The diffraction angles $26.2^{\circ}, 33.8^{\circ}$, and $51.7^{\circ}$ can be assigned to (110), (101), and (211) planes of the cassiterite structure of $\mathrm{SnO}_{2}$, respectively. The average grain size of ATO film deposited on the MWCNT buckypapers was $6.72 \mathrm{~nm}$. The average grain size of ATO film deposited on the stainless steel substrate at $10 \% \mathrm{O}_{2}$ partial pressure and $100 \mathrm{~W}$ RF power was $10.78 \mathrm{~nm}$.

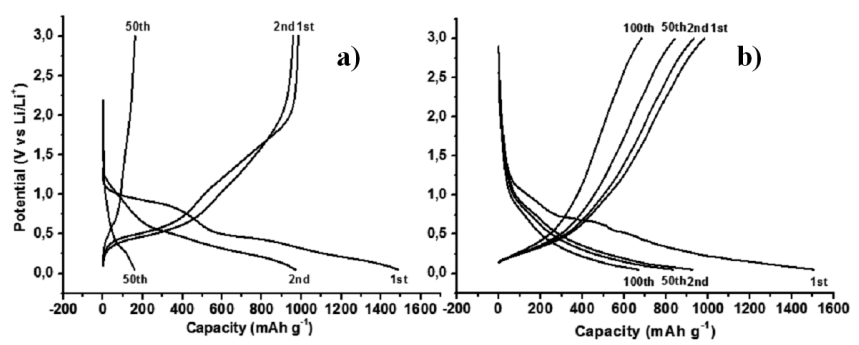

Fig. 4. The discharge/charge curves of anode materials: (a) ATO anode, (b) ATO-MWCNT nanocomposite anode.

Figure 4a shows the discharge and charge curves for cell made from the ATO anode material. First discharge capacity was $1486 \mathrm{mAh} \mathrm{g}^{-1}$ for ATO anode. The ATO anode demonstrated a discharge capacity of $158 \mathrm{mAh} \mathrm{g}^{-1}$ in the 50th cycle. The discharge and charge curves of ATO-MWCNT nanocomposite anode are given in Fig. 4b. The initial discharge capacity of ATO-MWCNT nanocomposite anode was $1506 \mathrm{mAh} \mathrm{g}^{-1}$. The discharge capacity of ATO-MWCNT nanocomposites anode decreased from $1506 \mathrm{mAh} \mathrm{g}^{-1}$ to $666 \mathrm{mAh} \mathrm{g}^{-1}$ after 100 cycles.

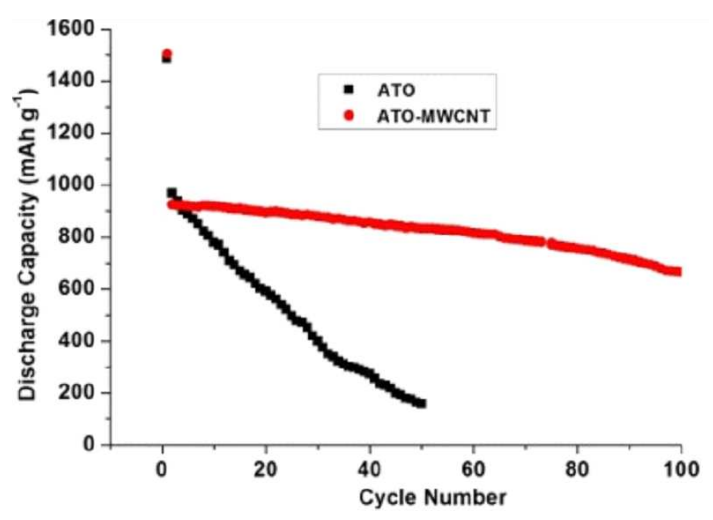

Fig. 5. The cyclic performances of ATO anode and ATO-MWCNT nanocomposite anode.

Figure 5 shows the cycling performances of ATO anode and ATO-MWCNT nanocomposite anode. The cycling performance of ATO-WMCNT nanocomposite anode is also better than ATO anode in 50 cycles. ATO anode displayed a fast capacity fading and the discharge capacity was reduced to below $160 \mathrm{mAh} \mathrm{g}^{-1}$ after 50 cycles. This poor cycling performance has long been understood as a sequence of particle aggregation and electrode pulverization.

\section{Conclusions}

The ATO-MWCNT anode shows high specific discharge capacity and very stable cycling stability up to 100 cycles compared to ATO anode. The MWCNT buckypaper provides flexible mechanical support with high electric conductivity. The advantage of using MWCNT buckypaper for a battery is not only their high electrical conductivity also it has extremely large surface area so it is easy for liquid to permeate to the inside.

\section{Acknowledgments}

This work is supported by the Scientific and Technological Research Council of Turkey (TÜBİTAK) under the contract number 109M464. The authors thank the TÜBİTAK MAG workers for their financial support.

\section{References}

[1] Y. Wang, T. Chen, Electrochim. Acta 54, 3510 (2009).

[2] Y. Idota, T. Kubota, A. Matsufuji, Y. Maekawa, T. Miyasaki, Science 276, 1395 (1997).

[3] T. Moon, C. Kim, S.T. Hwang, B. Park, Electrochem. Solid-State Lett. 9, A408 (2006).

[4] S.C. Nam, Y.H. Kim, W.I. Cho, B.W. Cho, H.S. Chun, K.S. Yun, Electrochem. Solid-State Lett. 2, 9 (1999).

[5] C. Kim, M. Noh, M. Choi, J. Cho, B. Park, Chem Mater. 17, 3297 (2005).

[6] M. Li, Q. Lu, Y. Nuli, X. Qian, Electrochem. SolidState Lett. 10, K33 (2007).

[7] G.F. Ortiz, R. Alcántara, J.L. Tirado, Electrochem. Solid-State Lett. 10, A286 (2007).

[8] Y. Wang, I. Djerdj, B. Smarsly, M. Antonietti, Chem. Mater. 21, 3202 (2009).

[9] P. Lian, X. Zhu, S. Liang, Z. Li, W. Yang, H. Wang, Electrochim. Acta 56, 4532 (2011).

[10] Y. Wang, F. Su, J.Y. Lee, X.S. Zhao, Chem. Mater. 18, 1347 (2006).

[11] F.D. Wu, M. Wu, Y. Wang, Electrochem. Commun. 13, 433 (2011).

[12] G. An, N. Na, X. Zhang, Z. Miao, S. Miao, K. Ding, Z. Liu, Nanotechnology 18, 435707 (2007).

[13] Y. Fu, R. Ma, Y. Shu, Z. Cao, X. Ma, Mater. Lett. 63, 1946 (2009).

[14] B.D. Cullity, Elements of X-ray Diffraction, AddisonWesley, Massachusetts 1956.

[15] B.C. Satishkumar, E.M. Vogl, A. Govindaraj, C.N.R. Rao, J. Phys. D, Appl. Phys. 29, 3173 (1996). 